\title{
Eotaxin-3 as a Plasma Biomarker for Mucosal Eosinophil Infiltration in Chronic Rhinosinusitis
}

\section{OPEN ACCESS}

Edited by:

Praveen Akuthota,

University of California, San Diego,

United States

Reviewed by:

Michaela Semeraro,

Necker-Enfants Malades Hospital,

France

Mats W. Johansson,

University of Wisconsin-Madison,

United States

*Correspondence:

Takechiyo Yamada

ymdtkcy@gmail.com

Specialty section: This article was submitted to

Molecular Innate Immunity,

a section of the journal

Frontiers in Immunology

Received: 14 June 2018 Accepted: 11 January 2019 Published: 04 February 2019

Citation:

Yamada T, Miyabe Y, Ueki S, Fujieda S, Tokunaga T, Sakashita M,

Kato Y, Ninomiya T, Kawasaki Y,

Suzuki S and Saito H (2019) Eotaxin-3 as a Plasma Biomarker for Mucosal Eosinophil Infiltration in Chronic Rhinosinusitis. Front. Immunol. 10:74. doi: 10.3389/fimmu.2019.00074

\begin{abstract}
Takechiyo Yamada ${ }^{1 *}$, Yui Miyabe ${ }^{1}$, Shigeharu Ueki ${ }^{2}$, Shigeharu Fujieda ${ }^{3}$, Takahiro Tokunaga ${ }^{3}$, Masafumi Sakashita $^{3}$, Yukinori Kato $^{3}$, Takahiro Ninomiya ${ }^{3}$, Yohei Kawasaki ${ }^{1}$, Shinsuke Suzuki ${ }^{1}$ and Hidekazu Saito ${ }^{1}$

' Department of Otorhinolaryngology, Head and Neck Surgery, Graduate School of Medicine, Akita University, Akita, Japan, ${ }^{2}$ Clinical Laboratory Medicine, Department of General Internal Medicine, Graduate School of Medicine, Akita University, Akita, Japan, ${ }^{3}$ Department of Otorhinolaryngology-Head and Neck Surgery, Faculty of Medical Science, University of Fukui, Fukui, Japan
\end{abstract}

Objective: Chronic rhinosinusitis with nasal polyps exhibits marked eosinophilic infiltration and its mucosal eosinophilia is associated with more severe symptoms. The Japanese epidemiological survey of refractory eosinophilic chronic rhinosinusitis found that patients with nasal polyps required multiple surgeries when there were higher infiltrating eosinophils in the mucosa. In order to identify plasma biomarkers for local eosinophil infiltration in rhinosinusitis for surgery, we examined the levels of molecules in the plasma of patients and compared the number of infiltrating eosinophils in the nasal mucosa.

Materials and Methods: Mucosal tissues from 97 patients with chronic rhinosinusitis (CRS) were obtained from the nasal polyps during surgery. Tissues were immediately fixed and sections were stained with hematoxylin-eosin. The number of eosinophils in the mucosa was counted at HPF (x 400). Blood samples were obtained and the plasma was stored at $-80^{\circ} \mathrm{C}$. We measured the plasma cytokine and chemokine levels using multiple assay systems according to the manufacturers' protocols. The tissues were divided into high- and low-eosinophil mucosal infiltration group for recurrence after endoscopic sinus surgery (ESS). We also observed chemokine secretion from nasal fibroblasts.

Results: The plasma level of eotaxin-3/ CC chemokine ligand 26 (CCL26) was significantly higher in the high-eosinophil mucosal infiltration group $(p<0.005)$. The number of infiltrating eosinophils in the mucosa was significantly higher in the group with the higher eotaxin-3 level $(p<0.001)$, but there was no significant difference in the blood eosinophil numbers among two groups. A significant positive correlation was found between the mucosal eosinophil count and the plasma levels of eotaxin-3 $(p<0.005)$. The levels of interleukin 33 (IL-33) $(p<0.001)$ and thymic stromal-derived lymphopoietin (TSLP) $(p<0.005)$ were significantly higher in the high-level eotaxin-3 group. IL-13 strongly induced the secretion of eotaxin-3 from human nasal fibroblasts $(p<0.05)$.

Conclusion: This is the first report suggesting eotaxin-3 as a plasma biomarker for mucosal eosinophil infiltration. Furthermore, the level of eotaxin-3 was found to be closely related to IL-33 and TSLP levels which indicate respiratory diseases. 


\section{INTRODUCTION}

Chronic rhinosinusitis demonstrates marked heterogeneity, both at the molecular pathophysiological level and at the clinical phenotype level. This disease is divided into 2 subgroups, chronic rhinosinusitis with nasal polyps (CRSwNP) and chronic rhinosinusitis without nasal polyps (CRSsNP) (1). Nasal polyps have negative effects on many aspects of the quality of life (physical health, general health, social functioning, sleep, mental health, and workplace absenteeism) due to nasal obstruction, olfactory disturbance, rhinorrhea, and symptoms caused by lower airway involvement $(2,3)$. In patients $80-90 \%$ of the nasal polyps are characterized by prominent eosinophilia (4). The clinical classification of CRSwNP according to the degree of eosinophilic infiltration in nasal polyps is controversial (5).

Eosinophilic chronic rhinosinusitis (ECRS) is an emerging classification of CRS, and is thought to more accurately reflect the underlying pathophysiology. There is a wide variation among reports, and no consensus currently exists regarding the cut off for the diagnosis of ECRS. Mucosal eosinophilia is defined as $>10$ eosinophils per high-power field (HPF) according to histopathology profiling and remodeling changes (6-8). On the other hand, mucosal eosinophilia defined as $\geq 70,>100$, or $>120$ mucosal eosinophils/HPF (9-11) is associated with poorer outcomes after endoscopic sinus surgery (ESS). A study conducted by 15 institutions participating in the Japanese epidemiological survey of refractory eosinophilic chronic rhinosinusitis revealed that the cut-off value of 70 mucosal eosinophils/HPF led to the most significant difference $(P<0.001)$ in the risk of recurrence in 1,716 patients treated by ESS (12).

T helper $1\left(\mathrm{~T}_{\mathrm{H}} 1\right)$ cells in patients with CRSsNP and $\mathrm{T}_{\mathrm{H}} 2$ cells in patients with CRSwNP are dominant $(13,14)$. In nasal polyps, immunoreactivity of the chemokine ligand (CCL) eotaxin subfamily comprising eotaxin-1 (CCL11), eotaxin-2 (CCL24), and eotaxin-3 (CCL26) was noted (15). Staphylococcus aureus enterotoxin B stimulation of dispersed nasal polyp cells induced significant interleukin 17A (IL-17A) synthesis (16). Thymic stromal-derived lymphopoietin (TSLP) was significantly increased in eosinophilic CRSwNP, and the expression of IL33 was enhanced in epithelial cells in both eosinophilic and non-eosinophilic CRSwNP compared with controls (17).

The nasal mucosal eosinophilic status provides prognostic information about disease severity and outcome of CRS including surgeries. In this study, we examined different molecules in order to identify a plasma biomarker for mucosal eosinophil infiltration in CRS patients with low- and high-risk requiring multiple surgeries, as well as the correlation between the nasal tissue eosinophil count and cytokine levels. The patients could be divided into two groups according to the molecular

\footnotetext{
Abbreviations: HPF, high-power field; CRSwNP, chronic rhinosinusitis with nasal polyps; CCL, chemokine ligand; CRSsNP, chronic rhinosinusitis without nasal polyps; ECRS, Eosinophilic chronic rhinosinusitis; ESS, endoscopic sinus surgery; IL, interleukin; ROC, receiver operating characteristic; AUC, area under the curve; TSLP, Thymic stromal-derived lymphopoietin; $\mathrm{T}_{\mathrm{H}} 2$, T helper 2; ELISA, enzymelinked immunosorbent assay; ILC2, innate lymphoid cells; BAFF, B cell activating factor; tPA, tissue plasminogen activator.
}

levels. Furthermore, the patients were divided into two groups according to the plasma levels, and mucosal eosinophils, blood eosinophils, and levels of other cytokines were evaluated. We also observed chemokine secretion from nasal polyp-derived fibroblasts.

\section{MATERIALS AND METHODS}

\section{Subjects}

We assessed patients with CRS treated by ESS. The diagnosis of sinus disease was based on patient history, clinical examination, and nasal endoscopy according to the guidelines of the European Position Paper on Rhinosinusitis and Nasal Polyps (18). Our study excluded patients who received systemic or topical corticosteroids before surgery, patients whose information on systemic or topical corticosteroids was unknown, patients who were followed up for $<28$ days after surgery, patients whose white blood cell count was $10,000 / \mu$ l or more, and patients from whom there was no pathological specimen. Preoperative demographics and medical history including sex, age, age of onset, reaction to drugs, smoking history, complications, and drug allergies, were obtained for each patient. Blood samples were taken to perform complete blood counts. This study was approved by the ethics committee of each institution including the general public through the Division of Otorhinolaryngology, Head \& Neck Surgery, University of Fukui. Nasal polyps were obtained from patients with CRS.

\section{Histological Analysis}

Mucosal tissues from patients with CRS were obtained from the nasal polyps or polypoid lesions of the ethmoid cavity during surgery. Tissues were immediately fixed in $10 \%$ formalin, embedded in paraffin, and cut into thin sections. Sections were stained with hematoxylin-eosin. The number of eosinophils in the mucosa was counted in HPF in the three densest areas with cellular infiltrate beneath the epithelial surface, and the mean number of eosinophils was calculated. Histological examinations were performed by three expert doctors blinded to the clinical data.

\section{Human Nasal Polyp-Derived Fibroblast Cell Culture}

Nasal polyp was obtained from patients with CRS during nasal surgery. Nasal specimens were cultured in $10 \mathrm{~cm}$ dishes containing RPMI 1640 medium (Nissui Pharmaceutical, Tokyo, Japan) supplemented with 10\% heat-inactivated FCS (Gibco, Grand Island, NY), $0.29 \mathrm{mg} / \mathrm{ml}$ glutamine, $100 \mathrm{U} / \mathrm{ml}$ penicillin, and $100 \mu \mathrm{g} / \mathrm{ml}$ streptomycin, at $37^{\circ} \mathrm{C}$ in $5 \% \mathrm{CO}_{2}$ and humidified air. Nasal fragments were removed and the first passage was performed. After a period of 3-4 weeks, nasal mucosa-derived fibroblast cell lines were established. The cells were used at passage numbers 3-5. Epithelial cells were confirmed not to be contaminated by immunohistochemical examination using cytokeratin and vimentin markers. The cells were cultured in the presence of IL-13 for appropriate periods, then culture supernatants were harvested and stored at $-80^{\circ} \mathrm{C}$. 


\section{Enzyme-Linked Immunosorbent Assay (ELISA)}

Blood samples were obtained and centrifuged immediately to prevent the degradation of complement components, and the plasma was stored at $-80^{\circ} \mathrm{C}$ within $1 \mathrm{~h}$ of blood collection. We measured the plasma levels of cytokines and the culture supernatants. We conducted multiple the assay system using Multiplex Assays (Millipore, Billerica, MA) according to the manufacturers' protocols.

\section{Statistical Analysis}

The non-parametric Mann-Whitney test was performed to evaluate differences. Correlation analysis was carried out using Spearman's rank correlation coefficient. We used a ROC (receiver operating characteristic) curve to calculate the area under the curve, and the closest point to top-left of ROC was determined as the optimal cut-off point. A $p$-value of $<0.05$ was considered statistically significant.

\section{RESULTS}

\section{The Cytokine Levels in Low- and High- Eosinophil Mucosal Infiltration}

A total of 67 males and 30 females aged 19 to 73 years old were included in the study. In the 37 patients that could be observed more than 3 years after surgeries, the ROC (receiver operating characteristic) curve for nasal mucosal eosinophil counts was used to discriminate the patients with recurrence from those without recurrence. Area under the curve (AUC) was 0.7533 ( $p=0.014$ ) (Figure 1). The optimal cut-off point of mucosal eosinophil counts was 55.0 infiltrating eosinophils/HPF to differentiate the subjects with recurrence from those without recurrence (with $64.0 \%$ sensitivity and $83.3 \%$ specificity). The

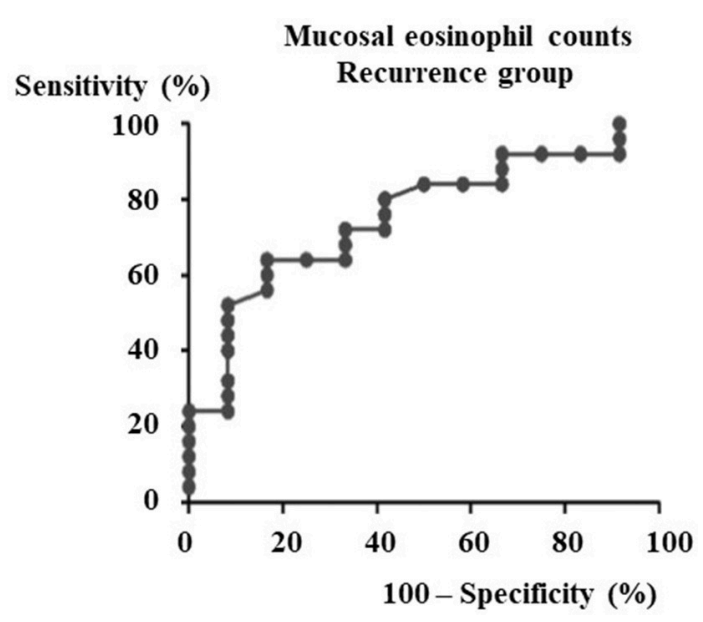

FIGURE 1 | ROC curve for recurrence group after ESS to determine the cut-off point of mucosal eosinophils number. From the data of the mucosal eosinophils number diagnostic test by ROC curve against the recurrence group after ESS (Area under the curve $=0.7533, p=0.014$ ), the cut-off level of mucosal eosinophils number is $55.0 \mathrm{pg} / \mathrm{ml}$. high-mucosal eosinophil infiltration group was defined as those having 55.0 or more infiltrating eosinophils/HPF in the mucosa. All others were in the low-risk group. Subject characteristics are presented in Table 1. In the low- $(n=54)$ and high- eosinophil mucosal infiltration $(n=43)$, the age (mean \pm SE) was 52.0 \pm 1.9 and $49.5 \pm 2.2$ years old, the mucosal eosinophil count $(/ \mathrm{HPF})$ was $26.2 \pm 2.2$ and $134.2 \pm 14.1(p<0.0001)$, the blood eosinophils (\%) were $5.0 \pm 0.6$ and $7.9 \pm 0.7(p<$ $0.0005)$, the blood neutrophils (\%) was $57.6 \pm 1.3$ and 54.4 \pm 1.6 , respectively. We next assessed the levels of eotaxin-1, eotaxin-2, eotaxin-3, IL-4, IL-5, IL-10, IL-12, IL-13, IL-21, IL33, TSLP, TNF $\alpha$, INF $\gamma$, IP-10, and MCP-1 in both groups. As shown in Table 2, the level of eotaxin-3 (84.3 \pm 5.3$)$ in the low-risk group was significantly lower than that $(1122.6 \pm 15.8)$ in the high-risk group $(p<0.005)$. There was no significant difference in the levels of other molecules including eotaxin1 , etaxin-2, or other cytokines, between the two groups in this study.

\section{Correlation Between Nasal Mucosal Eosinophil Count and the Plasma Cytokine Levels}

A plasma biomarker should be a significant relationship to mucosal eosinophil counts in CRS. The correlation coefficients $(\gamma)$ and $p$-value for comparison between mucosal eosinophil counts and the levels of eotaxin-1, eotaxin-2, eotaxin-3, IL4, IL-5, IL-10, IL-12, IL-13, IL-21, IL-33, TSLP, TNF $\alpha$, INF $\gamma$, IP-10, and MCP-1 were examined using the Spearman's rank correlation coefficient. As shown in Table 3, a significant positive correlation was found between the mucosal eosinophil count and the plasma level of eotaxin-3 $(p<0.005)$. We found no correlation between the mucosal eosinophil count and the levels of eotaxin-1, eotaxin-2, IL-4, IL-5, IL-10, IL-12, IL-13, IL-21, IL-33, TSLP, TNF $\alpha$, INF $\gamma$, IP-10, or MCP-1.

TABLE 1 | Demographics by eosinophil mucosal infiltration status for chronic rhinosinusitis groups.

\begin{tabular}{lcc}
\hline & $\begin{array}{c}\text { Low-eosinophil } \\
\text { mucosal infiltration } \\
(\boldsymbol{n}=\mathbf{5 4})\end{array}$ & $\begin{array}{c}\text { High-eosinophil } \\
\text { mucosal infiltration } \\
(\boldsymbol{n}=\mathbf{4 3})\end{array}$ \\
\hline Age (y) (Mean \pm SE) & $52.0 \pm 1.9$ & $49.5 \pm 2.2$ \\
Male, no./total (\%) & $36 / 54(66.7)$ & $31143(72.1)$ \\
Mucosal eosinophil & $26.2 \pm 2.2$ & $134.2 \pm 14.1^{\star \star \star}$ \\
counts (/HPF) & $5.0 \pm 0.6$ & $7.9 \pm 0.7^{\star \star}$ \\
Blood eosinophil (\%) & $57.6 \pm 1.3$ & $54.4+1.6$ \\
Blood neutrophil (\%) & & \\
(Mean \pm SE) & $11.1 \%(2 / 18)$ & $52.6 \%(10 / 19)^{\star}$ \\
Recurrence (\%) &
\end{tabular}

High-eosinophil mucosal infiltration group is defined when the numbers of infiltrating eosinophils are 55.0 or more than 55.0 / high-power field in the mucosa. The other is lowgroup. P-values for comparison between low- and high-eosinophil mucosal infiltration groups. The recunence rate is shown in the patients that could be observed more than 3 years after surgeries $\left({ }^{*} p<0.01,{ }^{* *} p<0.0005,{ }^{* * *} p<0.0001\right.$, ESS, endoscopic sinus surgery; HPF, per high-powered field). 
TABLE 2 | The plasma cytokine levels of low- and high-eosinophil mucosal infiltration groups.

\begin{tabular}{|c|c|c|c|}
\hline & $\begin{array}{c}\text { Low-eosinophil } \\
\text { mucosa I infiltration } \\
(n=54) \text { (Mean } \pm \text { SE) }\end{array}$ & $\begin{array}{l}\text { High-eosinophil mucosal } \\
\text { infiltration }(n=43) \\
\text { (Mean } \pm \text { SE) }\end{array}$ & $p$-value \\
\hline $\begin{array}{l}\text { Eotaxin-1 } \\
\text { (ng/ml) }\end{array}$ & $1.3 \pm 0.1$ & $1.1 \pm 0.1$ & 0.369 \\
\hline $\begin{array}{l}\text { Eotaxin-2 } \\
\text { (ng/ml) }\end{array}$ & $7.0 \pm 0.4$ & $6.0 \pm 0.4$ & 0.091 \\
\hline $\begin{array}{l}\text { Eotaxin-3 } \\
(\mathrm{pg} / \mathrm{ml})^{\star *}\end{array}$ & $84.3 \pm 5.3$ & $122.6 \pm 15.8$ & $0.002^{\star \star}$ \\
\hline IL-4 (pg/ml) & $164.8 \pm 20.6$ & $194.0 \pm 33.4$ & 0.974 \\
\hline IL-5 (pg/ml) & $132.9 \pm 108.7$ & $30.6 \pm 10.9$ & 0.918 \\
\hline IL-10 (pg/ml) & $156.8 \pm 118.5$ & $139.1 \pm 107.3$ & 0.318 \\
\hline IL-12 (pg/ml) & $56.4 \pm 30.3$ & $22.6 \pm 5.0$ & 0.305 \\
\hline IL-13 (pg/ml) & $138.5 \pm 109.2$ & $52.0 \pm 34.1$ & 0.139 \\
\hline IL-21 (pg/ml) & $26.8 \pm 2.4$ & $28.0 \pm 2.8$ & 0.476 \\
\hline IL-33 (pg/ml) & $57.6 \pm 18.4$ & $165.2 \pm 55.4$ & 0.768 \\
\hline TSLP (pg/ml) & $57.5 \pm 8.5$ & $82.6 \pm 17.3$ & 0.510 \\
\hline TNFa (pg/ml) & $59.4 \pm 6.5$ & $51.2 \pm 4.1$ & 0.633 \\
\hline INFy (pg/ml) & $26.2 \pm 7.2$ & $26.5 \pm 3.2$ & 0.933 \\
\hline IP-10 (pg/ml) & $843.6 \pm 118.3$ & $716.8 \pm 89.3$ & 0.645 \\
\hline MCP-1 (ng/ml) & $5.3 \pm 0.4$ & $5.2 \pm 0.4$ & 0.965 \\
\hline
\end{tabular}

$p$-values for comparison between low- and high- eosinophil mucosal infiltration groups $\left({ }^{* *} p<0.005\right)$.

\section{Tissue Eosinophil Infiltration and Blood Eosinophils Between High- and Low-Level Eotaxin-3 Groups}

The ROC curve for plasma eotaxin-3 levels was used to discriminate high-eosinophil mucosal infiltration group after ESS from the other group. The optimal cut-off point of plasma eotaxin-3 level was $78.8 \mathrm{pg} / \mathrm{ml}$ (with $61.4 \%$ sensitivity and $75.5 \%$ specificity) (Figure 2A). In the patients that could be observed more than 3 years after surgeries, the recurrence rate of lowlevel eotaxin-3 group (13.3\%) was significantly lower than that of high-level eotaxin-3 group $(45.5 \%)(p<0.05)$ (Figure 2B).

As shown in Figure 3, we divided the enrolled patients into two groups according to the plasma level of eotaxin-3. In lowlevel eotaxin-3 group $(n=42)$, the level of eotaxin-3 was $78.8 \mathrm{pg} / \mathrm{ml}$ or lower, whereas in the high-level eotaxin-3 group $(n=55)$, the level was higher than $78.8 \mathrm{pg} / \mathrm{ml}$. The nasal mucosal eosinophil count (mean $\pm \mathrm{SE}=47.5 \pm 7.9$ / HPF) was significantly lower in low-level eotaxin-3 group than in high-level eotaxin-3 group (mean $\pm \mathrm{SE}=94.4 \pm 12.9 / \mathrm{HPF})(p<0.001)$ (A). On the other hand, there was no significant difference in the percentage (B) or the number (C) of blood eosinophil between the two groups (low-level eotaxin-3 group: mean $\pm \mathrm{SE}=5.6 \pm$ $0.7 \%, 369.4 \pm 42.4 / \mathrm{ml}$ ) (high-level eotaxin-3 group: mean $\pm \mathrm{SE}$ $=6.8 \pm 0.6 \%, 433.6 \pm 36.2 / \mathrm{ml})$.

\section{Cytokine Levels Among High- and Low-Level Eotaxin-3 Groups}

We also compared the plasma levels of other cytokines between two groups according to the level of eotaxin-3 as in Figure 3. Figure 4A shows that the level of IL-33 (mean \pm SE $=175.0 \pm$
TABLE 3 | Correlation between nasal mucosal eosinophil counts and the plasma cytokine levels.

\begin{tabular}{lcl}
\hline & $\boldsymbol{\gamma}$ & $\boldsymbol{P}$-value \\
\hline Eotaxin-1 & -0.113 & 0.267 \\
Eotaxin-2 & -0.172 & 0.091 \\
Eotaxin-3 & 0.330 & $0.001^{\star *}$ \\
IL-4 & -0.065 & 0.525 \\
IL-5 & -0.007 & 0.944 \\
IL-10 & -0.038 & 0.708 \\
IL-12 & -0.148 & 0.147 \\
IL-13 & -0.186 & 0.069 \\
IL-21 & 0.148 & 0.148 \\
IL-33 & 0.041 & 0.691 \\
TSLP & 0.091 & 0.372 \\
TNF $\alpha$ & -0.149 & 0.148 \\
INF $\gamma$ & 0.111 & 0.273 \\
IP-10 & -0.073 & 0.474 \\
MCP-1 & 0.029 & 0.778 \\
\hline
\end{tabular}

Correlation coefficients $(\gamma)$ and P-value for comparison between mucosal eosinophil counts and the plasma cytokine levels were examined using the Speannan's conelation coefficient by rank. $\left.{ }^{* \star} p<0.005\right)$.

$44.4 \mathrm{pg} / \mathrm{ml}$ ) was significantly higher in high-level eotaxin-3 group than that (mean $\pm \mathrm{SE}=65.6 \pm 17.0 \mathrm{pg} / \mathrm{ml}$ ) in low-level eotaxin3 group $(p<0.001)$. The level of TSLP (mean $\pm \mathrm{SE}=84.8 \pm$ $14.5 \mathrm{pg} / \mathrm{ml}$ ) was also significantly higher in high-level eotaxin-3 group than those $($ mean $\pm \mathrm{SE}=47.4 \pm 7.9 \mathrm{pg} / \mathrm{ml})$ in low-level eotaxin-3 group $(p<0.005)$ (Figure 4B).

\section{IL-13-Induced Eotaxin-3 Protein Secretion in Human Nasal Polyp Fibroblasts}

TSLP and IL-33 are closely related to innate lymphoid cells (ILCs) and $\mathrm{T}_{\mathrm{H}} 2$ cells, inducing IL-4, IL-5, and IL-13 production. Since the expression of eotaxin-3 in human nasal fibroblast is quite unknown, we established fibroblast lines from small pieces of human nasal polyps respectively, from 8 individuals and then examined eotaxin-3 protein secretion in fibroblasts stimulated by IL-13 for $48 \mathrm{~h}$. As shown in Figure 5, IL-13 significantly enhanced the secretion of eotaxin- 3 in human nasal fibroblasts $(p<0.05)$, while we could not detect any increase of eotaxin- 1 or eotaxin-2. The eotaxin-3 production in the presence of IL-13 was strongly induced more than 240 times higher than in the absence of IL-13.

\section{DISCUSSION}

In this study, we found a significant positive correlation between the plasma level of eotaxin- 3 and the mucosal eosinophil count. The level of eotaxin-3 in high-eosinophil mucosal infiltration group was significantly higher than that in low- group $(p<$ 0.005). The nasal mucosal eosinophil counts, plasma IL-33 levels, and TSLP level were significantly higher in high-level eotaxin-3 group than those in low-level eotaxin-3 group. IL13 strongly induced the secretion of eotaxin-3 from human nasal fibroblasts. Based on research data, TSLP and IL-33 that 

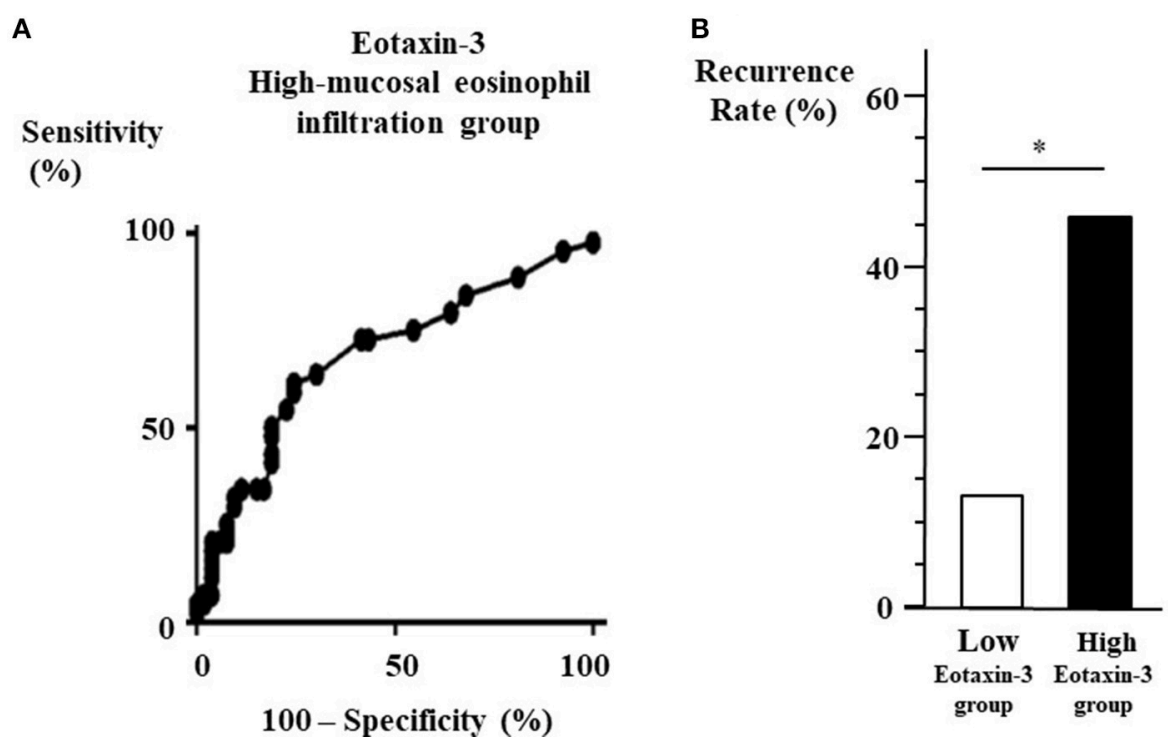

FIGURE 2 | (A) ROC curve for high-eosinophil mucosal infiltration group to determine the cut-off point of plasma eotaxin-3 level. From the data of the eotaxin-3 diagnostic test by ROC curve against the high-eosinophil mucosal infiltration group after ESS (Area under the curve $=0.6829, p=0.002$ ), the cut-off level of eotaxin-3 is $78.8 \mathrm{pg} / \mathrm{ml}$. (B) Recurrence rate between high- and low-level eotaxin-3 groups. The 37 patients that could be observed more than 3 years after surgeries were divided into two groups according to the plasma level of eotaxin-3. The recurrence rate in high-level eotaxin-3 group was higher than that in the other group ${ }^{*} p$ $<0.05)$.
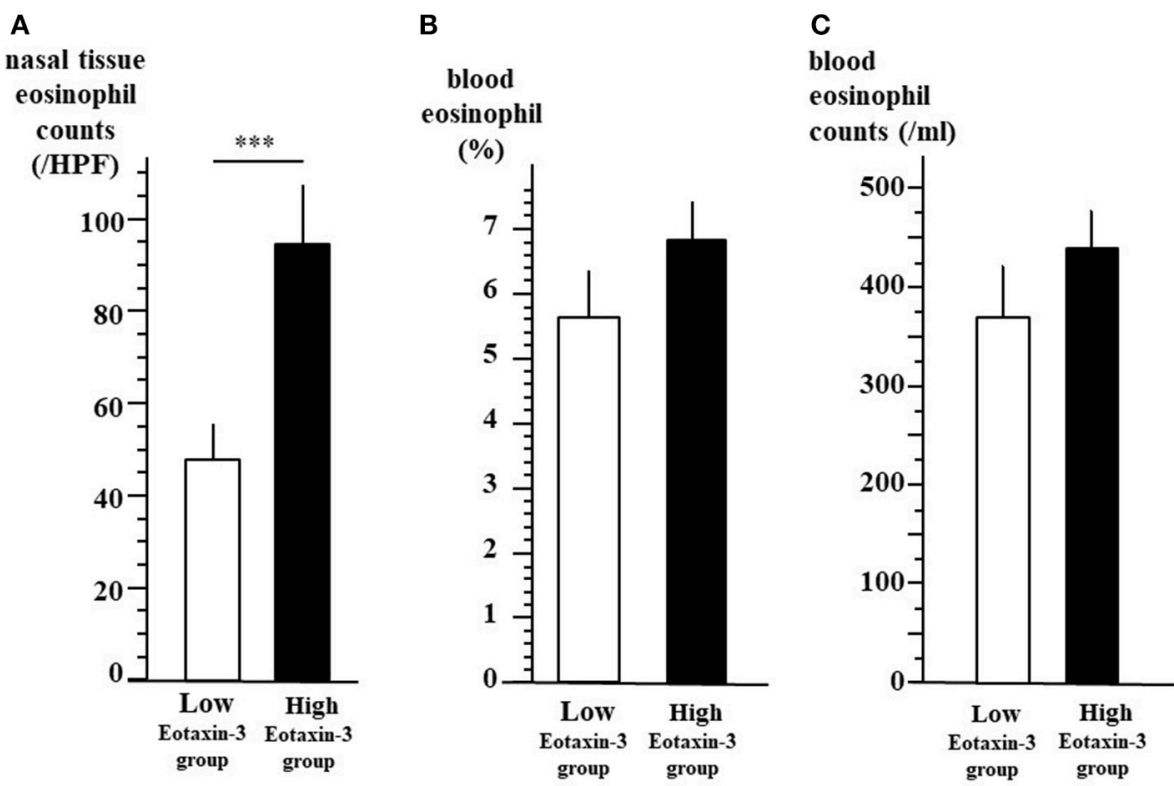

FIGURE 3 | Tissue eosinophil infiltration and blood eosinophils between high- and low-level eotaxin-3 groups. All the 97 patients were divided into two groups according to the plasma level of eotaxin-3. In low-level eotaxin-3 group, the level of eotaxin-3 was 78.8 pg/ml or lower. In the high-level eotaxin-3 group, the level of eotaxin-3 were higher than $78.8 \mathrm{pg} / \mathrm{ml}$. The mean \pm SE of the nasal mucosal eosinophil count per HPF (A), the percentage (B), and the number (C) of blood

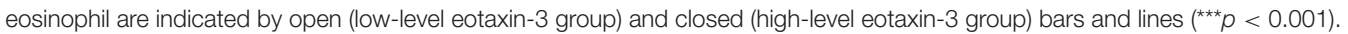

are secreted from epithelial cells and can induce type 2 ILCs and $\mathrm{T}_{\mathrm{H}} 2$ cells, and then the levels of IL-4, IL-5, and IL-13 increase. IL-13 induces eotaxin-3 production from fibroblasts and epithelial cells. Eotaxin-3 induced the tissue infiltration of eosinophils (Figure 6A). Thus, eotaxin-3 could function in pathology of mucosal eosinophil infiltration in CRSwNP. Bronchial epithelial cell injury leads to production of type 2 alarmins such as IL-33 and TSLP, also in asthma. Type 2 ILCs 
A

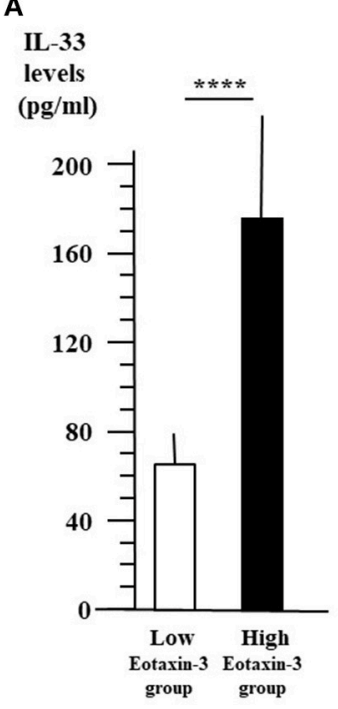

\section{B}

\section{TSLP}

levels $\quad * * *$

(pg/ml)

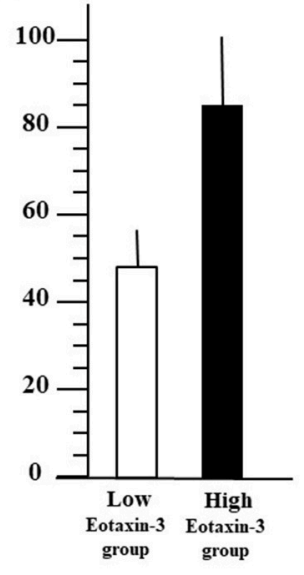

FIGURE 4 | IL-33 and TSLP levels between high- and low-level eotaxin-3 groups. The patients were divided into two groups according to the plasma level of eotaxin-3 as in Figure 2. The mean \pm SE of plasma IL-33 (A) and TSLP levels (B) are indicated with the open (low-level eotaxin-3 group) and closed (high-level eotaxin-3 group) bars and lines $\left({ }^{\star \star * *} p<0.001,{ }^{* \star \star} p<0.005\right)$.

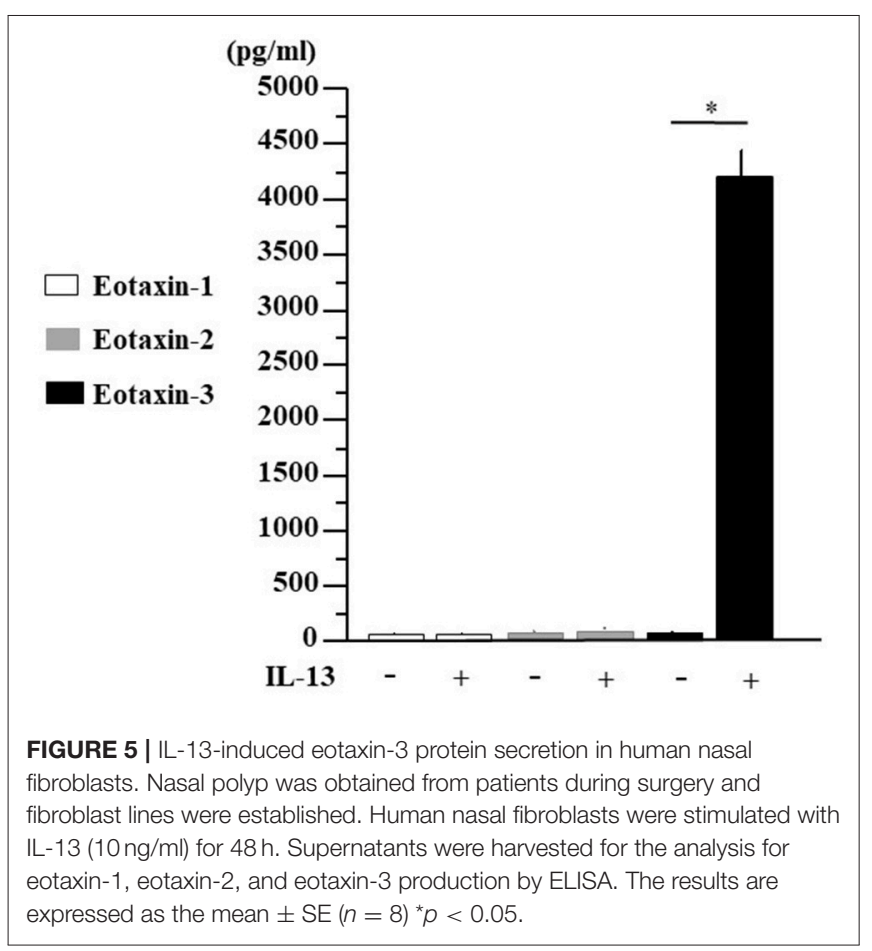

produce, in response to TSLP or IL-33, large amounts of the $\mathrm{T}_{\mathrm{H}} 2$ cytokines IL-5, IL-13 and, to a lesser extent, IL-4 $(19,20)$. Eotaxin-3 is the most efficient eotaxin to induce the migration or transmigration of eosinophils (21). The hematoxylin-eosin staining shows eosinophils infiltrate also in the tissue of CRS (Figure 6B).
Eosinophil-predominant disorders are closely related to allergic diseases, such as asthma, allergic rhinitis, atopic dermatitis, eosinophilic esophagitis. The eotaxin-3 expression was found optimal from the data set to define type 2 inflammation based on airway mucosal IL-13-driven gene expression and how this related to clinically accessible biomarkers for patients with mild to severe asthma and non-atopic healthy control subjects (22). Allergic subjects have a significant immediate response of nasal symptoms as well as a significant increase significantly raising levels of eotaxin-3 after nasal allergen challenge (23). The gene expression level for eotaxin-3 was higher in skin changes of atopic dermatitis patients (24). The serum eotaxin-3 level was significantly higher in patients with urticaria than in the healthy controls (25). The pathogenesis of eosinophilic esophagitis depends on local epithelial immune activation with production of eotaxin-3 and TSLP (26). On the microarray, 1,999 genes were differentially expressed between eosinophilic gastritis in children and the controls $(p<0.05)$, including significant upregulation of eotaxin-3 (27).

Precision medicine (28) is medical treatment that precisely classifies the patient's condition to select a suitable treatment method, personal medical care, and tailor-made medical treatment. Moreover, for CRS or allergic diseases, biomarkers, genetic factors, relationships with environmental factors, and phenotypes are often separated for therapy $(29,30)$. Defining endotypes can help clinicians predict disease prognosis, and select subjects suitable for a specific therapy for CRS (31). CRS is caused by dysregulated immunological responses inducing various mediators and inflammatory cells, including innate lymphoid cells, TSLP, and IL-33, which are mainly secreted by epithelial cells in response to external stimuli. They then act on type 2 ILCs and Th2 cells, inducing IL-4, IL-5, and IL-13. In this study, IL-33 and TSLP levels were significantly higher in the highlevel eotaxin-3 group than those in the low-level eotaxin-3 group. We noted the significant positive correlation between the plasma levels of eotaxin-3 and IL-33 $(p<0.001)$ or TSLP $(p<0.005)$.

$\mathrm{T}_{\mathrm{H}} 2$ cytokines (IL-4 or IL-13) play important roles in CRS. IL-4 or IL-13 induce TSLP production by nasal fibroblasts (32). Local IgE and B cell activating factor (BAFF, BLyS) production are also signature characteristics of nasal polyps (33). IL-4 induces class switch recombination to IgE with the CD40 ligand, BAFF, and BLyS (34). IL-4 and IL-13 also down-regulate tissue plasminogen activator ( $t-P A)$ in epithelial cells while t-PA activates fibrinolysis cascades involve in fibrin deposition and dissolution (35). IL-13 stimulation of human nasal epithelial cells dominantly induced eotaxin-3 expression (36). We also found IL-13 significantly increased eotaxin-3 production by human nasal fibroblasts. The strong induction of eotaxin- 3 from nasal tissue, high levels of eotaxin-3 in nasal polyp (36), and its expression of endothelial cells (15) could keep the plasma high levels of eotaxin-3 in the patients with ECRS. The nasal mucosal eosinophil count was significantly 2 times higher in plasma high-level eotaxin-3 group than in low-level eotaxin-3 group. The blood eosinophil count was 1.2 times higher in high-level eotaxin-3 group than in low-level eotaxin-3 group while there was no significant difference in the percentage or the number 

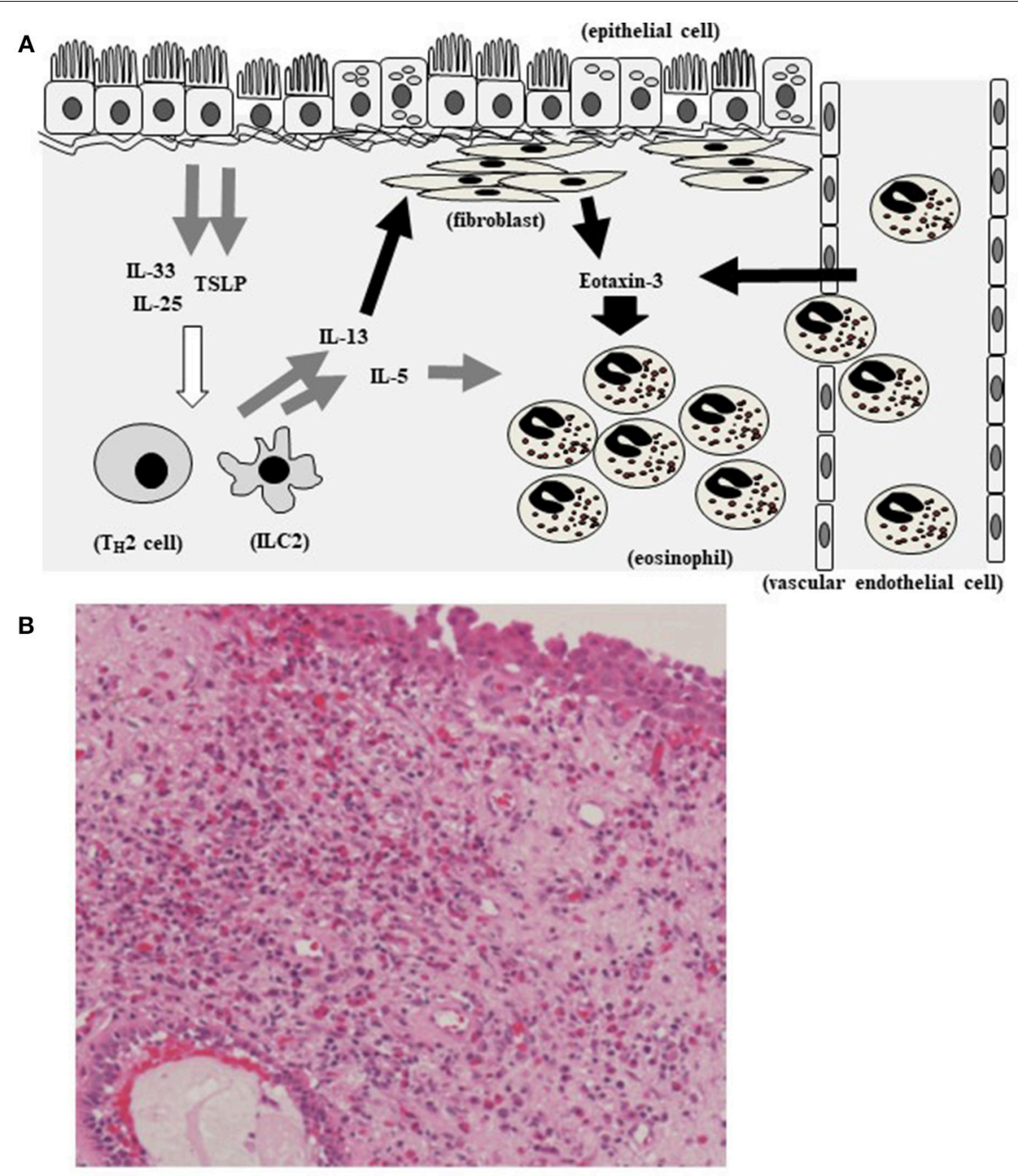

FIGURE 6 | Hypothetical model showing eotaxin-3 and eosinophil infiltration in CRS. TSLP and IL-33 that are secreted by epithelial cells and act on type 2 ILCs and $\mathrm{T}_{\mathrm{H}} 2$ cells, inducing IL-5 and IL-13. IL-13 induces eotaxin-3 production from fibroblasts and epithelial cells. Eotaxin-3 induced the tissue infiltration of eosinophils (A). Eosinophils infiltrate in the tissue of CRS (The section is stained with hematoxylin-eosin) (B).

of blood eosinophil between the two groups. Increased eotaxin-3 levels in tissue could induce mucosal infiltration of eosinophils more strongly compared with the increase of blood eosinophils. And, the recurrence rate of high-level eotaxin-3 group was significantly 3 times higher than that of low-level eotaxin-3 group for 3 years after surgeries $(p<0.05)$. Dupilumab is a fully human monoclonal antibody against the IL-4 receptor $\alpha$ subunit, which inhibits signaling of IL-4 and IL-13. Of note, during this trial, the serum eotaxin-3 levels decreased and then nasal polyp scores began to decrease. On the other hand, the blood eosinophil count did little change in the group using dupilumab (37).

Human monoclonal antibodies are available or under clinical trials in allergic disease or refractory CRS. $\mathrm{T}_{\mathrm{H}} 2$ cytokines such as IL-4, IL-5, IL-13, epithelial-derived cytokines such as TSLP, IL-33, and acquired immunity markers including IgE could be candidates for molecular targets. In the randomized, double- blind, placebo-controlled study on the effects of humanized monoclonal anti-IgE antibody, omalizumab on NP and comorbid asthma (38), omalizumab reduced the total nasal endoscopic polyp score and demonstrated significant benefits for nasal and respiratory symptoms, such as nasal congestion, anterior rhinorrhea, loss of smelling sense, wheezing, and dyspnea. On the contrary, there was no reduction in inflammatory mediators in the treated group. Eosinophils, mast cells, and ILC2s mainly produce IL-5. The anti-IL- $5 \mathrm{mAb}$, reslizumab reduced the polyp size, blood eosinophilic counts, and ECP concentration in nasal secretions (39). Responders had higher IL-5 levels in nasal secretions compared with non-responders. In the clinical trial of the anti-IL-5 mAb, mepolizumab, there was significant improvement in the nasal polyposis severity, VAS score, endoscopic nasal polyp score, and all individual VAS symptom scores in the mepolizumab compared with placebo 
groups (40). However, it remains unclear which biomarker can be used to select good responders to anti-IL-5 treatment. Dupilumab can inhibit signaling of IL-4 and IL-13 central to $\mathrm{T}_{\mathrm{H}}$ 2-cell-mediated inflammation. Its clinical efficacy for $\mathrm{T}_{\mathrm{H}} 2$ cell-mediated diseases of asthma and atopic dermatitis has been confirmed and it also improved the nasal symptoms in perennial allergic rhinitis and comorbid asthma (41). A randomized clinical trial demonstrated a potential role of dupilumab in NP by significantly decreasing the nasal polyp score $(p<0.001)$ and improving in olfaction and CT scores $(p<0.001)$, as well as other clinical outcomes such as nasal symptoms and quality of life (37). Significant improvements with dupilumab were also observed for the 22 -item sinonasal symptoms $(p<0.001)$. The serum eotaxin-3 levels decreased within 2 weeks, nasal polyp scores began to decrease at 4 weeks, and then sinonasal symptoms improved gradually. The serum levels of total IgE also decreased thereafter.

As CRS involves several mechanisms with high heterogeneity and different therapeutic responses, biomarkers and endotyping $(42,43)$ help to determine the optimal primary therapeutic modality, select good responder to a specific treatment, and predict treatment outcomes. In this study, the significant positive correlation between the plasma levels of eotaxin-3 and the mucosal eosinophil count support the ability of dupilumab to reduce nasal mucosal eosinophil infiltration against little change of blood eosinophil counts. Dupilumab can reduce the blood eotaxin-3 levels that are significantly higher in the high-risk group for recurrence after surgery. Also proton pump inhibitors can decrease eotaxin-3 expression in patients with CRSwNP (36). Eotaxin-3 levels could be one of the suitable plasma biological

\section{REFERENCES}

1. Hastan D, Fokkens WJ, Bachert C, Newson RB, Bislimovska J, Bockelbrink A, et al. Chronic rhinosinusitis in Europe-an underestimated disease. A GA(2) LEN study. Allergy (2011) 66:1216-023. doi: 10.1111/j.1398-9995.2011.02646.x

2. Alobid I, Benitez P, Bernal-Sprekelsen M, Roca J, Alonso J, Picado C, et al. Nasal polyposis and its impact on quality of life: comparison between the effects of medical and surgical treatments. Allergy (2005) 60:452-8. doi: 10.1111/j.1398-9995.2005.00725.x

3. Sahlstrand-Johnson P, Ohlsson B, Von Buchwald C, Jannert M, AhlnerElmqvist M. A multi-centre study on quality of life and absenteeism in patients with CRS referred for endoscopic surgery. Rhinology (2011) 49:420-8. doi: 10.4193/Rhino11.101

4. Stoop AE, van der Heijden HA, Biewenga J, van der Baan S. Eosinophils in nasal polyps and nasal mucosa: an immunohistochemical study. J Allergy Clin Immunol. (1993) 91:616-22. doi: 10.1016/0091-6749(93)90267-J

5. Jiang N, Kern RC, Altman KW. Histopathological evaluation of chronic rhinosinusitis: a critical review. Am J Rhinol Allergy (2013) 27:396-402. doi: 10.2500/ajra.2013.27.3916

6. Ho J, Hamizan AW, Alvarado R, Rimmer J, Sewell WA, Harvey RJ. Systemic predictors of eosinophilic chronic rhinosinusitis. Am J Rhinol Allergy (2018) 32:252-7. doi: 10.1177/1945892418779451

7. Snidvongs K, Lam M, Sacks R, Earls P, Kalish L, Phillips PS, et al. Structured histopathology profiling of chronic rhinosinusitis in routine practice. Int Forum Allergy Rhinol. (2012) 2:376-85. doi: 10.1002/alr.21032

8. Barham HP, Osborn JL, Snidvongs K, Mrad N, Sacks R, Harvey RJ. Remodeling changes of the upper airway with chronic rhinosinusitis. Int Forum Allergy Rhinol. (2015) 5:565-72. doi: 10.1002/alr.21546 parameters for the efficacy of dupilumab or proton pump inhibitors in CRS. This may be a breakthrough in the treatment of recalcitrant CRS. Further studies including multivariate analysis are needed to investigate the potential use of monoclonal antibodies as adjunct therapy or with other medications or surgery.

\section{ETHICS STATEMENT}

This study was carried out in accordance with the recommendations of Declaration of Helsinki with written informed consent from all subjects. All subjects gave written informed consent in accordance with the Declaration of Helsinki. The protocol was approved by the ethics committee of each institution including the general public through the Division of Otorhinolaryngology, Head and Neck Surgery, University of Fukui.

\section{AUTHOR CONTRIBUTIONS}

TY, HS, and YM: conception and design; TY, HS, YM, SU, TT, MS, YKat, TN, SF, YKaw, and SS: analysis and interpretation; TY, HS, and YM: drafting the manuscript for important intellectual content.

\section{FUNDING}

This study was supported by a Grant-in-Aid for Scientific Research (KAKENHI), (B) Grant Number 25293348, and (C) Grant Number 17K11356.
9. Nakayama T, Yoshikawa M, Asaka D, Okushi T, Matsuwaki Y, Otori N et al. Mucosal eosinophilia and recurrence of nasal polyps - new classification of chronic rhinosinusitis. Rhinology (2011) 49:392-6. doi: 10.4193/Rhino10.261

10. Matsuwaki Y, Ookushi T, Asaka D, Mori E, Nakajima T, Yoshida T, et al. Chronic rhinosinusitis: risk factors for the recurrence of chronic rhinosinusitis based on 5-year follow-up after endoscopic sinus surgery. Int Arch Allergy Immunol. (2008) 146:77-81. doi: 10.1159/000126066

11. Ikeda K, Shiozawa A, Ono N, Kusunoki T, Hirotsu M, Homma H, et al. Subclassification of chronic rhinosinusitis with nasal polyp based on eosinophil and neutrophil. Laryngoscope (2013)123:E1-9. doi: 10.1002/lary.24154

12. Tokunaga T, Sakashita M, Haruna T, Asaka D, Takeno S, Ikeda H, et al. Novel scoring system and algorithm for classifying chronic rhinosinusitis: the JESREC Study. Allergy (2015) 70:995-1003. doi: 10.1111/all.12644

13. Van Zele T, Claeys S, Gevaert P, Van Maele G, Holtappels G, Van Cauwenberge $P$, et al. Differentiation of chronic sinus diseases by measurement of inflammatory mediators. Allergy (2006) 61:1280-9. doi: 10.1111/j.1398-9995.2006.01225.x

14. Van Bruaene N, Perez-Novo CA, Basinski TM, Van Zele T, Holtappels G, De Ruyck N, et al. T-cell regulation in chronic paranasal sinus disease. J Allergy Clin Immunol. (2008) 121:1435-41, e1-3. doi: 10.1016/j.jaci.2008.02.018

15. Yao T, Kojima Y, Koyanagi A, Yokoi H, Saito T, Kawano K, et al. Eotaxin-1,-2, and-3 immunoreactivity and protein concentration in the nasal polyps of eosinophilic chronic rhinosinusitis patients. Laryngoscope (2009) 119:1053-9. doi: 10.1002/lary.20191

16. Makihara S, Okano M, Fujiwara T, Kariya S, Noda Y, Higaki T, et al. Regulation and characterization of IL-17A expression in patients with chronic rhinosinusitis and its relationship with eosinophilic inflammation. J Allergy Clin Immunol. (2010) 126:397-400. doi: 10.1016/j.jaci.2010.05.014 
17. Liao B, Cao PP, Zeng M, Zhen Z, Wang H, Zhang YN, et al. Interaction of thymic stromal lymphopoietin, IL-33, and their receptors in epithelial cells in eosinophilic chronic rhinosinusitis with nasal polyps. Allergy (2015) 70:1169-80. doi: 10.1111/all.12667

18. Fokkens WJ, Lund VJ, Mullol J, Bachert C, Alobid I, Baroody F, et al. European position paper on rhinosinusitis and nasal polyps. Rhinol Suppl. (2012) 50:1-298. doi: 10.4193/Rhino50E2

19. Larose MC, Archambault AS, Provost V, Laviolette M, Flamand N. Regulation of eosinophil and group 2 innate lymphoid cell trafficking in asthma. Front Med. (2017) 4:136. doi: 10.3389/fmed.2017.00136

20. Doran E, Cai F, Holweg CTJ, Wong K, Brumm J, Arron JR. Interleukin13 in asthma and other eosinophilic disorders. Front Med. (2017) 4:139. doi: 10.3389/fmed.2017.00139

21. Provost V, Larose MC, Langlois A, Rola-Pleszczynski M, Flamand N, Laviolette M. CCL26/eotaxin-3 is more effective to induce the migration of eosinophils of asthmatics than CCL11/eotaxin-1 and CCL24/eotaxin-2. J Leukoc Biol. (2013) 94:213-22. doi: 10.1189/jlb.0212074

22. Silkoff PE, Laviolette M, Singh D, FitzGerald JM, Kelsen S, Backer V, et al. Identification of airway mucosal type 2 inflammation by using clinical biomarkers in asthmatic patients. J Allergy Clin Immunol. (2017) 140:710-9. doi: 10.1016/j.jaci.2016.11.038

23. Baumann R, Rabaszowski M, Stenin I, Tilgner L, Scheckenbach K, Wiltfang J, et al. Comparison of the nasal release of IL-4, IL-10, IL17, CCL13/MCP-4, and CCL26/eotaxin-3 in allergic rhinitis during season and after allergen challenge. Am J Rhinol Allergy (2013) 27:266-72. doi: 10.2500/ajra.2013.27.3913

24. Owczarek W, Paplinska M, Targowski T, Jahnz-Rózyk K, Paluchowska E, Kucharczyk A, et al. Analysis of eotaxin 1/CCL11, eotaxin 2/CCL24 and eotaxin 3/CCL26 expression in lesional and non-lesional skin of patients with atopic dermatitis. Cytokine (2010) 50:181-5. doi: 10.1016/j.cyto.2010.02.016

25. Lu T, Jiao X, Si M, He P, Zou J, Zhang S, et al. The correlation of serums CCL11, CCL17, CCL26, and CCL27 and disease severity in patients with urticaria. Dis Markers (2016) 2016:1381760. doi: 10.1155/2016/1381760

26. Spergel J, Aceves SS. Allergic components of eosinophilic esophagitis. J Allergy Clin Immunol. (2018) 142:1-8. doi: 10.1016/j.jaci.2018.05.001

27. Sato M, Shoda T, Shimizu H, Orihara K, Futamura K, Matsuda A, et al. Gene expression patterns in distinct endoscopic findings for eosinophilic gastritis in children. J Allergy Clin Immunol Pract. (2017) 5:1639-49. doi: 10.1016/j.jaip.2017.03.030

28. Collins FS, Varmus H. A new initiative on precision medicine. $N$ Engl J Med. (2015) 372:793-5. doi: 10.1056/NEJMp1500523

29. Oberle AJ, Mathur P. Precision medicine in asthma: the role of bronchial thermoplasty. Curr Opin Pulm Med. (2017)23:254-60. doi: 10.1097/MCP.0000000000000372

30. De Greve G, Hellings PW, Fokkens WJ, Pugin B, Steelant B, Seys SF. Endotype-driven treatment in chronic upper airway diseases. Clin Transl Allergy (2017) 7:22. doi: 10.1186/s13601-017-0157-8

31. Kim DW, Cho SH. Emerging endotypes of chronic rhinosinusitis and its application to precision medicine. Allergy Asthma Immunol Res. (2017) 9:299306. doi: 10.4168/aair.2017.9.4.299

32. Nonaka M, Fukumoto A, Ogihara N, Sakanushi A, Pawankar R, Yagi T. Synergistic induction of thymic stromal lymphopoietin by tumor necrosis factor alpha and Th2 cytokine in nasal polyp fibroblasts. Am J Rhinol Allergy (2010) 24:e14-8. doi: 10.2500/ajra.2010.24.3436

33. Dilidaer, Zheng $\mathrm{Y}$, Liu $\mathrm{Z}, \mathrm{Hu} \mathrm{X}$, Zhang $\mathrm{J}$, Hu L, et al. Increased BAFF expression in nasal polyps is associated with local IgE production, Th2 response and concomitant asthma. Eur Arch Otorhinolaryngol. (2017) 274:1883-90. doi: 10.1007/s00405-016-4435-1

34. Yamada $T$, Zhang $\mathrm{K}$, Yamada A, Zhu D, Saxon A. B lymphocyte stimulator activates p38 mitogen-activated protein kinase in human Ig class switch recombination. Am J Respir Cell Mol Biol. (2005) 32:388-94. doi: $10.1165 / \mathrm{rcmb} .2004-$ 0317OC

35. Takabayashi T, Kato A, Peters AT, Hulse KE, Suh LA, Carter R, et al. Excessive fibrin deposition in nasal polyps caused by fibrinolytic impairment through reduction of tissue plasminogen activator expression. Am J Respir Crit Care Med. (2013)187:49-57. doi: 10.1164/rccm.201207-1292OC

36. Min JY, Ocampo CJ, Stevens WW, Price CPE, Thompson CF, Homma T, et al. Proton pump inhibitors decrease eotaxin-3/CCL26 expression in patients with chronic rhinosinusitis with nasal polyps: Possible role of the nongastric H,K-ATPase. J Allergy Clin Immunol. (2017) 139:130-41.e11. doi: $10.1016 /$ j.jaci.2016.07.020

37. Bachert C, Mannent L, Naclerio RM, Mullol J, Ferguson BJ, Gevaert P, et al. Effect of subcutaneous dupilumab on nasal polyp burden in patients with chronic sinusitis and nasal polyposis: a randomized clinical trial. JAMA (2016) 315:469-79. doi: 10.1001/jama.2015.19330

38. Gevaert P, Calus L, Van Zele T, Blomme K, De Ruyck N, Bauters W, et al. Omalizumab is effective in allergic and nonallergic patients with nasal polyps and asthma. J Allergy Clin Immunol. (2013)131:110-6.e1. doi: 10.1016/j.jaci.2012.07.047

39. Gevaert P, Lang-Loidolt D, Lackner A, Stammberger H, Staudinger H, Van Zele T, et al. Nasal IL-5 levels determine the response to anti-IL-5 treatment in patients with nasal polyps. J Allergy Clin Immunol. (2006)118:1133-41. doi: 10.1016/j.jaci.2006.05.031

40. Bachert C, Sousa AR, Lund VJ, Scadding GK, Gevaert P, Nasser $\mathrm{S}$, et al. Reduced need for surgery in severe nasal polyposis with mepolizumab: randomized trial. J Allergy Clin Immunol. (2017) 140:1024-31. doi: 10.1016/j.jaci.2017.05.044

41. Weinstein SF, Katial R, Jayawardena S, Pirozzi G, Staudinger H, Eckert L, et al. Efficacy and safety of dupilumab in perennial allergic rhinitis and comorbid asthma. J Allergy Clin Immunol. (2018) 142:171-7. doi: 10.1016/j.jaci.2017.11.051

42. Ninomiya T, Noguchi E, Haruna T, Hasegawa M, Yoshida T, Yamashita $\mathrm{Y}$, et al. Periostin as a novel biomarker for postoperative recurrence of chronic rhinosinitis with nasal polyps. Sci Rep. (2018) 8:11450. doi: 10.1038/s41598-018-29612-2

43. Kato Y, Takabayashi T, Sakashita M, Imoto Y, Tokunaga T, Ninomiya T, et al. The expression and functional analysis of CST1 in intractable nasal polyps. Am J Respir Cell Mol Biol. (2018) 59:448-57. doi: 10.1165/rcmb.2017-0325OC

Conflict of Interest Statement: The authors declare that the research was conducted in the absence of any commercial or financial relationships that could be construed as a potential conflict of interest.

Copyright (c) 2019 Yamada, Miyabe, Ueki, Fujieda, Tokunaga, Sakashita, Kato, Ninomiya, Kawasaki, Suzuki and Saito. This is an open-access article distributed under the terms of the Creative Commons Attribution License (CC BY). The use, distribution or reproduction in other forums is permitted, provided the original author(s) and the copyright owner(s) are credited and that the original publication in this journal is cited, in accordance with accepted academic practice. No use, distribution or reproduction is permitted which does not comply with these terms. 